\title{
AISI 1050 Çelik Malzemenin Delinmesinde Tepki Kuvvetini Etkileyen Parametrelerin Yüzey Yanıt Yöntemi ile Analizi
}

\author{
Zülküf DEMIIR ${ }^{1 *}$, Sehmus BADAY ${ }^{2}$, Fikret SÖNMEZ $^{3}$ \\ ${ }^{1}$ Makine Mühendisliği Bölümü, Mühendislik Mimarlık Fakültesi, Batman Üniversitesi, Batman, Türkiye \\ ${ }^{2}$ Makine ve İmalat Mühendisliği Bölümü, Teknoloji Fakültesi, Batman Üniversitesi, Batman, Türkiye \\ ${ }^{3}$ Karşıyaka TÜPRAŞ Mesleki ve Teknik Anadolu Lisesi, Kocaeli, Türkiye \\ *1 zulkuf.demir@batman.edu.tr ${ }^{2}$ sehmus.baday@batman.edu.tr, ${ }^{3}$ sonmezfikret@ gmail.com
}

Öz: : Delme işlemi, geleneksel imalat yöntemleri arasında talaşlı imalat işlemlerinin yaklaşık olarak \%33'ünü oluşturmaktadır. $\mathrm{Bu}$ işleminin imalat alanındaki önemine rağmen matkabın uç açısı, fener mili devri, ilerleme miktarı ve delinen malzemenin özellikleri gibi birçok parametre delik delme işlemini etkilemektedir. Bu amaçla gerçekleştirilen bu deneysel çalışmada, farklı uç açılarına sahip matkaplar ile delme işlemi esnasında meydana gelen tepki kuvveleri Yüzey Yanıt Yöntemi (YYY) ile analiz edilmiştir. İtme kuvvetlerini meydana getiren üç farklı fener mili devir sayısı, ilerleme miktarı ve matkap uç açıları seçilerek toplam 27 adet deney gerçekleştirilmiştir. Deney parametrelerine bağlı olarak en iyi tepki kuvvetini tahmin etmek için oluşturulan YYY üç seviyeli ve üç faktörlü Box-Behnken tasarım yöntemi dikkate alınarak oluşturulmuştur. Deney sonuçlarından elde edilen tepki kuvvetleri, birinci dereceden ve ikinci dereceden matematiksel modeller oluşturulmuştur. Elde edilen bu modellerin etkinliği ANOVA testi yapılarak parametrelerin etkinliği araştırılmıştır. Sonuç olarak parametrelerin tepki kuvvetleri üzerindeki etkinliği karşılaştııılmış ve en etkili parametrenin ilerleme miktarı olduğu tespit edilmiştir. Ayrıca rastgele seçilen deney verileri ile YYY ile oluşturulan modeller karşılaştırılmış 0,964 R2 değeri elde edilmiştir. YYY ile delme işleminde meydana gelen tepki kuvvetlerinin değerleri çok küçük hata oranlarında tahmin edebildiği belirlenmiştir.

Anahtar kelimeler: Delme işlemi, itme kuvveti, yüzey yanıt yöntemi, ANOVA

\section{Analysis of the Parameters Effecting Thrust Force in Drilling Process with Response Surface Method}

\begin{abstract}
Drilling process accounts for approximately 33\% of machining processes among conventional manufacturing methods. Despite the importance of this process in the manufacturing field, many parameters such as the point angle of the drill, spindle speed, feed rate and properties of the drilled material affect the drilling process. Accordingly, in this study which was employed experimentally, Response Surface Method (RSM) was used to analyses the thrust forces occurring during the drilling process with different point angles of drill. A total of 27 experiments were carried out using three different spindle speeds, feed rates and point angles with drill, which generated thrust forces. In order to estimate the best thrust force which was based on the experimental parameters, the surface response method was created by considering the three-level and threefactor Box-Behnken design method. The first and second order mathematical models were developed for the thrust forces which were obtained from the experimental results. ANOVA test was used to investigate the effectiveness of parameters on these models which were obtained by RSM. As a result, the effectiveness of the parameters on the thrust forces were compared and it was determined that the most effective parameter was feed rate. In addition, randomly selected experimental data were compared with the models generated by RSM, and a R2 value of 0.964 was obtained. It was determined that RSM can predict the values of thrust forces at a very high rate.
\end{abstract}

Key words: Drilling process, thrust force, response surface method, ANPOVA.

\section{Giriş}

Delik delme işlemi, geleneksel imalat yöntemleri arasında talaşlı imalat işlemlerinin yaklaşık olarak yüzde otuz üçünü oluşturmaktadır [1]. İmalat alanında oldukça geniş bir uygulama alanına sahip olan bu delik delme

\footnotetext{
* Sorumlu yazar: zulkuf.demir@ batman.edu.tr. Yazarların ORCID Numarası: ${ }^{10000-0002-0685-3712, ~}{ }^{20000-0003-4208-8779,}{ }^{3} 0000-0003-$ $1718-892 \mathrm{X}$
} 
işlemi, yüksek hassasiyet ve yüksek kaliteli işlem gerekliliğini de beraberinde getirmektedir. Ancak bu işlemdeki birçok parametrenin delik kalitesi üzerindeki etkisi, araştırmacıların çoğunu bu alanda farklı çalışmalar yapmaya itmiştir [2]. Delme işlemini etkileyen bu parametreler; matkabın uç açısı, matkap ve delinen malzemenin özellikleri gibi birçok parametre bu operasyonu doğrudan etkilemektedir. Bununla birlikte, takım malzemesi, matkap aşınması, yüzey kalitesi, talaşın boyutları ve biçimi, boyutsal doğruluk gibi hassasiyeti belirleyen bu parametreler delik delme işlemi sonuçlarını değiştirmektedir [3]. İlerleme hızındaki artış ile talaş kalınlığ ve tepki kuvveti artarken kesme hızının artışı ile azalırlar. Matkap ya da delik çapının artışı ile takım-iş parçası temas alanı artacağından tepki kuvveti de artar [4, 5]. Delme işleminde meydana gelen tepki kuvveti, yüzey pürüzlülüğü, delik çapının boyutsal değişimini ve talaş kalınlığı gibi sonuçları etkileyen en önemli bir parametredir [6]. Ayrıca, tepki kuvveti, matkap özünün ve boşluk açısının artması ile önemli oranda artarken uç açısı ve helis açısının artması ile azalır [7, 8]. Fakat hem tepki kuvveti hem de yüzey pürüzlülüğü ilerleme miktarı ve matkap uç açısının artması ile artarlar [9].

Talaşlı imalat işlemlerinde uygun seçilemeyen parametreler kesici takımın hızlı aşınmasına, kesme kuvvetlerinin ve yüzey pürüzlülüğü gibi değerlerin artmasına sebep olmaktadır. Bu artışlar takım ömrünü ve işleme maliyetlerini doğrudan etkilemektedir. Bu doğrultuda deney tasarımı yöntemleri, maliyetleri düşürmek ve aynı zamanda en iyi ve en doğru ölçü tamlığında kalite ürünler elde edilmesi amaçlanmaktadır. Bununla birlikte gerçekleştirilen deneyleri en verimli şekilde yapabilme ve deney sonuçlarını doğru analiz edilebilmesi açısından son derece önemlidir. Deney tasarım yöntemleri arasında YYY optimizasyon problemlerinin çözümünde hızlı ve etkili bir metot olarak ortaya çıkmaktadır. Bu yöntem ile delik delme işlemleri sonucunda oluşan tepki kuvvetleri etki eden işleme parametrelerinin optimizasyonunu gerçekleştirilmiştir. İtme kuvveti ile ilgi yapılan ve optimizasyon yöntemleri ile ilgili yapılan çalışmalar aşağıda özetlenmiştir.

Kyratsis ve ark., gerçekleştirmiş oldukları çalışmada Al-7075 malzemesinin işleme parametrelerine (kesme hızı, ilerleme miktarı ve matkap çapı) bağlı olarak delinmesinde elde edilen tepki kuvvetleri ve kesme torkunu tahmin etmek için YYY'ni kullanmışlardır. YYY ile elde etmiş oldukları matematiksel modeller ve ANOVA bağlı olarak tepki kuvveti ve kesme torku üzerindeki işleme parametrelerinin etkisini ortaya koymuşlardır. Sonuç olarak tepki kuvveti ve kesme torku üzerinde matkap çapı ve ilerleme miktarı doğrudan etki ederken, kesme hızının önemli bir derecede etki etmediğini tespit etmişlerdir [10]. Raja ve ark., GFRP kompozit malzemesinin yüksek hızda delinmesi sonucunda meydana gelen tepki kuvveti ve delaminasyon (katman ayrılması) faktörünü YYY ile incelemişlerdir. Çalışmanın sonucunda tepki kuvveti ve delaminasyon faktörü üzerinde fener mil devri ve matkap çapına göre ilerleme miktarının daha etkili olduğunu tespit etmişlerdir [11]. Efkolidis ve ark., Al-7075 malzemesinin delinmesi sonucunda oluşan tepki kuvveti ve kesme torkunu tahmin etmek ve modellemek için YYY ve yapay sinir ağları kullanmışlardır. Bu iki model tepki kuvveti ve kesme torku sonuçlarını doğru bir şekilde tahmin ettiğini fakat yapay sinir ağları tahminlerinin deney sonuçlarına daha yakın tahmin ettiği belirtmişlerdir [12]. Valarmathi ve ark., çalışmalarında deney sayısını belirlemek için Taguchi deney tasarımı yöntemi kullanarak delik delme deneylerini gerçekleştirmişlerdir. Yapılan deneyler sonucunda elde etmiş oldukları tepki kuvvetlerini tahmin etmek için YYY ile matematiksel modeller oluşturmuşlardır. Ayrıca tepki kuvvetini etkileyen parametrelerin etkisini görmek için ANOVA testi de yapmışlarıdır. Sonuç olarak yüksek fener mili devri ile birlikte düşük ilerleme miktarının tepki kuvvetlerini düşürdüğünü tespit etmişlerdir [13]. Palanikumar ve Muniaraj kompozit malzemenin delinmesinde giriş parametresi olarak fener mili devri, ilerleme miktarı ve matkap çaplarına seçerek tepki kuvvetlerini tahminini yapan bir YYY modeli oluşturmuşlardır. YYY ile elde etmiş oldukları matematiksel denklemler ile deney sonuçları karşılaştırmışlarıdır. Giriş parametrelerinin tepki kuvveti üzerinde etkileri bakımından karşılaştırıldığın en etkili parametrenin ilerleme miktarı olduğunu bildirmişlerdir [14]. Metal matrisli kompozit delinmesinde fener mili devri, ilerleme miktarı ve matkap uç acısının malzeme kaldırma oranı ve yüzey pürüzlülüğü üzerindeki etkilerini araştırmak için YYY'ni kullanmışlardır. Her bir giriş parametresi için üç seviyeli belirleyerek YYY ile matematiksel modeller elde etmişlerdir. Giriş parametrelerin çıkış parametreleri ile olan ilişkilerini tespit etmek için ANOVA testi yapmışlardır. Sonuç olarak bu modelleme yöntemiyle çııı̧ parametrelerini giriş parametrelerine bağlı olarak tahminini etkin bir şekilde elde etmişlerdir [15]. Anarghya ve ark., yapmış oldukları çalışmada, tepki ve tork kuvvetlerini tahmin etmek için YYY ve yapay sinir ağları genetik algoritma modellemelerini kullanmışlardır. Her iki modelleme sonuçlarını karşılaştırmış ve YSA-GA nın YYY den daha iyi tahmin elde ettiğini bulmuşlarıdır. Sonuç olarak tepki kuvveti üzerinde kesi uç matkap açısının önemli parametre olduğunu ve tork kuvvetini ise matkap çapında biraz etkilendiğini tespit etmişlerdir [16]. Shuang Yi ve ark., Ti-6Al-4V titanyum alaşımının kesme parametresine bağlı olarak delinmesi sonucunda takım aşınması, tepki kuvveti, yüzey pürüzlülüğü ve talaş morfolojisini incelemişlerdir. Gerçekleştirilen çalışmanın sonucunda tepki kuvvetinin ilerleme miktarının artmasıyla arttığını tespit etmişleridir [17]. Shunmugesh ve ark. polimerce güçlendirilmiş karbon fiber takviyeli kompozit malzemenin işlenmesinde elde edilen tepki, tork kuvvetlerini ve 
yüzey pürüzlülük değerlerini YYY ve ANN ile tahmin etmişlerdir. ANN çoklu YYY göre daha iyi tahmin sonuçlarını verdiğini bulmuşlardır [18].

$\mathrm{Bu}$ çalışmada, farklı uç açılarına sahip matkaplar, fener mili devri ve ilerleme miktarı parametrelerine bağlı olarak delik delme işlemleri esnasında oluşan tepki kuvvetleri YYY ile değerlendirilmiştir. Gerçekleştirilen bu çalışmanın amacı YYY ile delik delme işlemlerinde önemli bir çıktısı olan tepki kuvvetleri birinci dereceden ve ikinci dereceden tam etkileşimli matematiksel olarak modelleyerek, tepki kuvveti değerlerini optimum bir şekilde tahmin etmektir.

\section{Materyal ve Metot}

Delik delme deneylerinde, günümüz imalat sanayisinde geniş bir kullanım alanına sahip olan 100x100x15 mm ebatlarında levha plaka kullanılmıştır. İşleme deneyleri Şekil 1(a)'deki MEXUS 510 C-II Model Mazak dik işleme CNC tezgâhında gerçekleştirilmiştir. Delik delme işlemleri öncesinde $5 \mathrm{~mm}$ çaplı matkap ile ön delik delme işlemleri yapılmıştır. Delik delme işlemi sırasına oluşan tepki kuvvetleri Şekil 1(b)'deki Kistler 5233A dinamometre yardımı ile ölçülmüştür. AISI 1050 çeliği $5 \mathrm{~mm}$ çapındaki matkapla ile $13 \mathrm{~mm}$ derinlikte soğutma sıv1 kullanarak 50,27 m/dak kesme hızı ve $0,1 \mathrm{~mm} /$ dak ilerleme miktarında ön delik delme işlemi gerçekleştirilmiştir. Daha sonra ön delik işlemi yapılan bu noktalar Tablo 1'de verilen parametrelere bağlı olarak 10 mm çapındaki matkap ile delinmiştir.

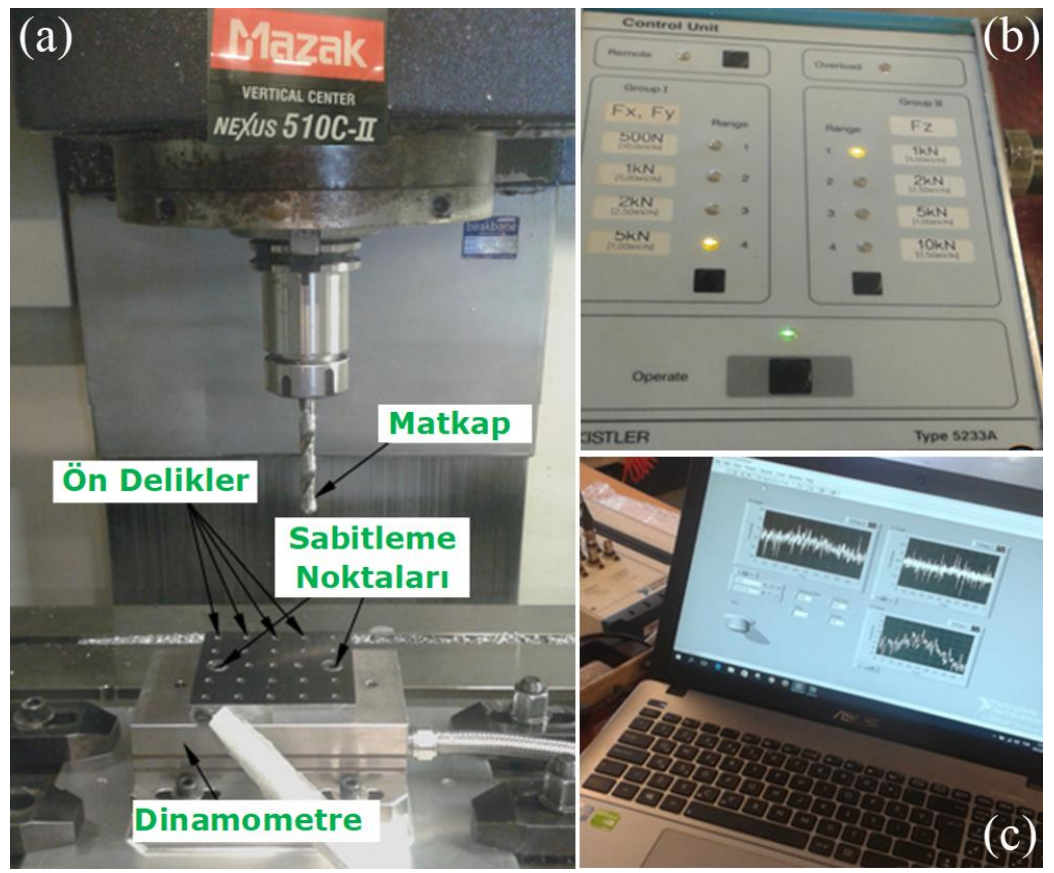

Şekil 1. Deney düzeneği, a) CNC freze tezgâhı, b)5233 A tip dinamometre, c) bilgisayar.

HSS matkap uç açıları oluşturmak için matkap taşlama tezgâhında (Şekil 2(a)) üç farklı açıda 100, 118 ve 136 derece olmak üzere bilenerek şekillendirilmiştir. Taşlama sonucunda oluşan kesici uçların uç açı formları Şekil 2 (b)'de verilmiştir.

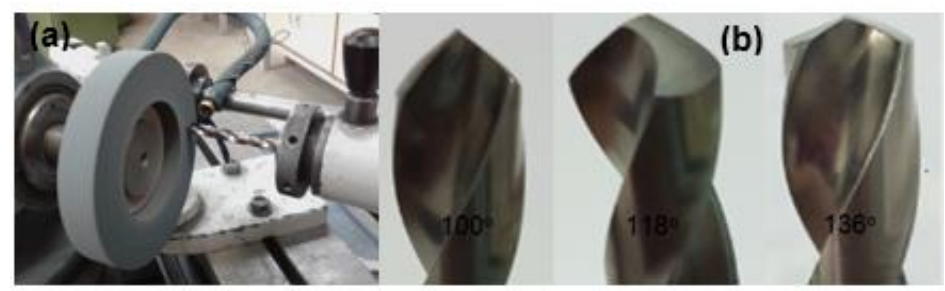

Şekil 2. a) Takım bileme makinesi, b) değişik uç açılı matkap uçları. 
Delme deneylerinde kullanılan kesme parametreleri ve matkap özellikleri Tablo 1'de verilmiştir. Deney düzeneğinin oluşturan parametreler ve deneylerin yapılma aşaması Şekil 3'de şematik olarak gösterilmiş̧ir.

Tablo 1. Deney parametreleri ve matkap ucunun geometrik özellikleri.

\begin{tabular}{|l|l|}
\hline Kesme hızı $(\mathrm{m} /$ dak.) sabit & $\mathrm{V}=50.27$ \\
\hline İlerleme miktarı $(\mathrm{mm} / \mathrm{dev})$ & $\mathrm{f} 1=0.025, \mathrm{f} 2=0.050, \mathrm{f} 1=0.075$ \\
\hline Matkap çapı $(\mathrm{mm})$ & $10 \pm 0,01$ \\
\hline Matkap türü & 2 Ağızlı HSS \\
\hline Matkap uç açısı (Derece) & $100,118,136$ \\
\hline Helis açısı (Derece) & 30 \\
\hline Matkap sapının uzunluğu $(\mathrm{mm})$ & 46 \\
\hline Matkap sapının biçimi & Silindirik \\
\hline
\end{tabular}

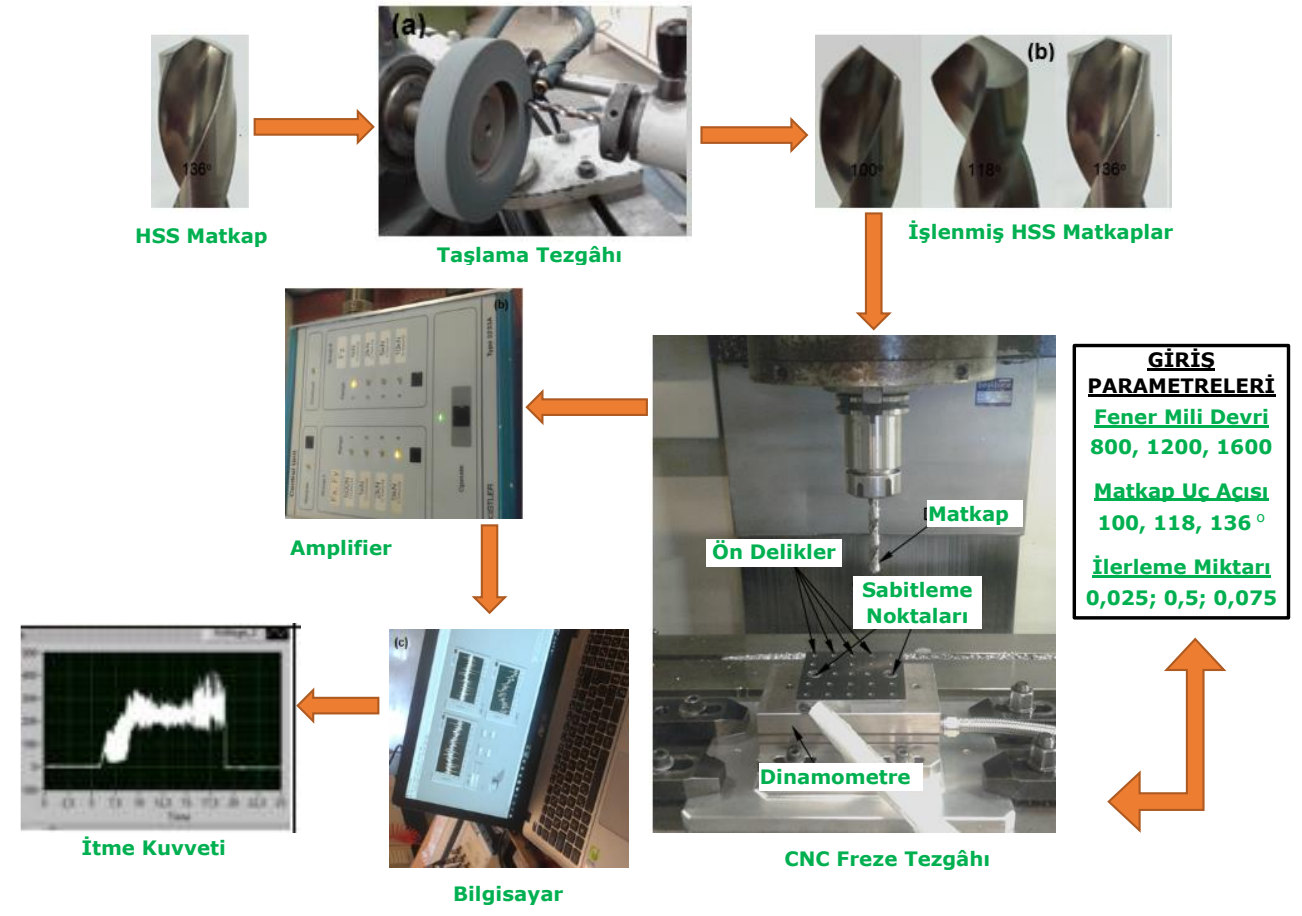

Şekil 3. Deney düzeneğinin şematik gösterimi.

\section{Yüzey Yanıt Yöntemi}

Yüzey yanıt yöntemi bir deney tasarım yöntemi olarak yanıtın (tepkinin) farklı deney parametrelerden etkilendiği durumlarda kullanılmaktadır. Bu yöntemde matematik ve istatistik teknikler bir arada kullanılarak problemlere çözüm aranmaktadır. [19-21]. Mühendislik problemlerinin çözümünde faklı matematiksel modeller ile çözüm kümesinin elde edilmesi hedeflenmektedir. Yüzey yanıt yöntemin kullanılmasında da farklı denklem sistemleri tercih edilebilmektedir. Bununla birlikte bu yöntem ile genel olarak lineer denklem sistemi temel alınarak modeller geliştirilmektedir. Bu çalışmada, çözümü amaçlanan bu deney tasarım sistemi için iki farklı model ile iki farklı matematiksel eşitlik kullanılmıştır. İlk olarak birinci dereceden denkleme ait olan modelin genel formülünün gösterimi Eşitlik 1'de verilmiştir.

$Y=\beta 0+\beta 1 X 1+\beta 2 X 2+\beta 3 X 3$

Kullanılan ikinci matematiksel eşitlikte ise birinci eşitlikten farklı olarak yeni terimler modele eklenmiştir. Parametrelerin kareleri ve parametrelerin birbirleri çarpımı da eşitliğe dâhil edilmiş̧ir. Oluşturulan bu ikinci dereceden matematiksel denklemin temel yapısı Eşitlik 2'de görüldüğü gibidir. 
$F=\beta 0+\beta 1 x d+\beta 2 x s+\beta 3 x f_{z}+\beta 4 x d^{2}+\beta 5 x s^{2}+\beta 6 x f_{z}^{2}+\beta 7 x d x s+\beta 8 x d x f_{z}+\beta 9 x s x$

$F=$ Tepki Kuvveti; $s=$ Fener Mili Devri; $\quad d=\mathrm{Uç}$ Açısı; $f z=$ İlerleme Miktarı;

Farklı parametrelerin kullanıma bağlı olarak oluşan tepki kuvvetlerinin etkisinin incelendiği bu deney tasarımında Box-Behnken tasarım yaklaşımı tercih edilmiştir. YYY tasarımında girdi parametreleri belirlenirken, her değişken için alfa parametreleri kullanılmaktadır. Bu parametre değeri 1,682 ve 1 olarak belirlenebilmektedir. Merkezi kompozit tasarım yöntemlerinden olan CCC ve CCI yöntemlerinde Alfa değeri 1,682 olmaktadır. Bu durum parametre değerlerini beș kademe oluşturarak (beș seviyeli) yapma zorunluluğunu ortaya çıkarmaktadır [19-21]. Gerçekleştirilen bu çalışmada kullanılan Box-Behnken yönteminde ise Alfa değeri 1 alınarak, her parametre için üç seviyeden oluşan bir model oluşturulmuştur. Deneylerde kullanılan parametreler ve parametrelerin seviyeleri gösteren değerler Tablo 2'de verilmiştir.

Tablo 2. Kullanılan parametreler ve seviyeler.

\begin{tabular}{|c|c|c|c|c|c|c|c|c|c|}
\hline Parametreler & \multicolumn{3}{|c|}{ Fener Mili Devri (s) } & \multicolumn{3}{|c|}{ Uç Açısı (d) } & \multicolumn{3}{|c|}{ İlerleme Miktarı (fz) } \\
\hline Birimi & (dev/dak) & & & (derece) & & & (mm/dak) & & \\
\hline Seviyeler & Seviye -1 & Seviye 0 & Seviye 1 & Seviye -1 & Seviye 0 & Seviye 1 & Seviye -1 & Seviye 0 & Seviye 1 \\
\hline Seviyelerin Değerleri & 800 & 1200 & 1600 & 100 & 118 & 136 & 0,025 & 0,05 & 0,075 \\
\hline
\end{tabular}

Tablo 2.'de görülen üç parametrenin her biri için üç seviye belirlendiğinden dolayı toplam $3 \times 3 \times 3=27$ deney yapılması gerekmektedir. YYY kullanılan bu deney sisteminde ise modelleme için 15 veri girişi yapılmıştır. Her deneyden bir veri girişi yapılırken ortalama değerleri içeren (1200 dev/dak, $118^{\circ}$ ve $\left.0.05 \mathrm{~mm} / \mathrm{dak}\right)$ deney verisi için deney üç kez tekrar edilerek veri girişi yapılmaktadır. Böylelikle toplam 13 farklı deney için 15 veri girişi ile sistem modellenmektedir. Deney sisteminde kullanılan veriler Tablo 3'de görülmektedir.

Tablo 3. Deney tasarımı ve testlerde kullanılan veriler.

\begin{tabular}{|c|c|c|c|c|}
\hline \multirow{2}{*}{$\begin{array}{l}\text { Fener Mili Devri (s) } \\
\text { (dev/dak) }\end{array}$} & \multirow[b]{2}{*}{ Uç Açısı (d) (derece) } & \multirow[b]{2}{*}{$\begin{array}{l}\text { İlerleme Miktarı (fz) } \\
\text { (mm/dak) }\end{array}$} & \multirow[b]{2}{*}{ Tepki Kuvveti (F) (N) } & Yüzey Yanıt Yöntemi \\
\hline & & & & $\begin{array}{l}\text { Model verileri (13 Deney -15 Veri) } \\
\text { X=Yapılan Deney Sayısı }\end{array}$ \\
\hline 800 & 100 & 0,025 & 472,43 & \\
\hline 1200 & 100 & 0,025 & 292,09 & $X$ \\
\hline 1600 & 100 & 0,025 & 274,7 & \\
\hline 800 & 118 & 0,025 & 423,86 & $\mathrm{X}$ \\
\hline 1200 & 118 & 0,025 & 407,12 & \\
\hline 1600 & 118 & 0,025 & 388,95 & $\mathrm{X}$ \\
\hline 800 & 136 & 0,025 & 420,25 & \\
\hline 1200 & 136 & 0,025 & 288,54 & $\mathrm{X}$ \\
\hline 1600 & 136 & 0,025 & 261,05 & \\
\hline 800 & 100 & 0,05 & 784,3 & $\mathrm{X}$ \\
\hline 1200 & 100 & 0,05 & 694,9 & \\
\hline 1600 & 100 & 0,05 & 487,25 & $\mathrm{X}$ \\
\hline 800 & 118 & 0,05 & 506,44 & \\
\hline 1200 & 118 & 0,05 & 481,32 & XXX \\
\hline 1600 & 118 & 0,05 & 414,92 & \\
\hline 800 & 136 & 0,05 & 498,56 & $X$ \\
\hline 1200 & 136 & 0,05 & 435,84 & \\
\hline 1600 & 136 & 0,05 & 403,97 & $X$ \\
\hline 800 & 100 & 0,075 & 985,04 & \\
\hline 1200 & 100 & 0,075 & 844,71 & $\mathrm{X}$ \\
\hline 1600 & 100 & 0,075 & 697,6 & \\
\hline 800 & 118 & 0,075 & 897,79 & $\mathrm{X}$ \\
\hline 1200 & 118 & 0,075 & 848,26 & \\
\hline 1600 & 118 & 0,075 & 623,73 & $X$ \\
\hline 800 & 136 & 0,075 & 566,15 & \\
\hline 1200 & 136 & 0,075 & 522,68 & $\mathrm{X}$ \\
\hline 1600 & 136 & 0,075 & 490,27 & \\
\hline
\end{tabular}


Modelleme çalışmalarında öncelikle birinci derece matematiksel denklem kullanılmıştır. Bu model ile çözümleme işlemi yapıldıktan sonra ise ikinci derece tam etkileşim model ile çözüm aranmıştır. Her iki denklem ile oluşturulan modellerin değerlendirilmesinde ANOVA analizi kullanılmıştır. Yapılan ANOVA analizi sonucu elde edilen değerler Tablo 4'de görülmektedir.

Tablo 4. Modellere ait ANOVA analizleri.

\begin{tabular}{||l|l|l|l|l|l|}
\hline Birinci Derece Model \\
\hline Kaynak & DF & Adj SS & Adj MS & F Değeri & $\begin{array}{l}\text { P } \\
\text { Değeri }\end{array}$ \\
\hline Model & 3 & 401219 & 133740 & 18,79 & 0,000 \\
\hline Lineer & 3 & 401219 & 133740 & 18,79 & 0,000 \\
\hline s & 1 & 61357 & 61357 & 8,62 & 0,014 \\
\hline d & 1 & 60309 & 60309 & 8,47 & 0,014 \\
\hline fz & 1 & 279554 & 279554 & 39,27 & 0,000 \\
\hline Hata & 11 & 78310 & 7119 & & \\
\hline Uyumsuzluk & 9 & 78310 & 8701 & & \\
\hline Saf Hata & 2 & 0 & 0 & & \\
\hline Toplam & 14 & 479529 & & & \\
\hline
\end{tabular}

\begin{tabular}{||l|l|l|l|l|l|}
\hline İkinci Dereceden Tam Etkileşimli Model \\
\hline Kaynak & DF & Adj SS & Adj MS & F Değeri & $\begin{array}{l}\text { P } \\
\text { Değeri }\end{array}$ \\
\hline Model & 9 & 477677 & 53075 & 143,32 & 0,000 \\
\hline Lineer & 3 & 401219 & 133740 & 361,14 & 0,000 \\
\hline s & 1 & 61357 & 61357 & 165,68 & 0,000 \\
\hline d & 1 & 60309 & 60309 & 162,85 & 0,000 \\
\hline fz & 1 & 279554 & 279554 & 754,88 & 0,000 \\
\hline Kare & 3 & 26555 & 8852 & 23,90 & 0,002 \\
\hline s x s & 1 & 23271 & 23271 & 62,84 & 0,001 \\
\hline d x d & 1 & 1091 & 1091 & 2,95 & 0,147 \\
\hline fz x fz & 1 & 1932 & 1932 & 5,22 & 0,071 \\
\hline İlişkiler & 3 & 49903 & 16634 & 44,92 & 0,000 \\
\hline s x d & 1 & 10248 & 10248 & 27,67 & 0,003 \\
\hline s x fz & 1 & 14298 & 14298 & 38,61 & 0,002 \\
\hline d x fz & 1 & 25357 & 25357 & 68,47 & 0,000 \\
\hline Hata & 5 & 1852 & 370 & & \\
\hline Uyumsuzluk & 3 & 1852 & 617 & & \\
\hline Saf Hata & 2 & 0 & 0 & & \\
\hline Toplam & 14 & 479529 & & & \\
\hline & & & & & \\
\hline
\end{tabular}

Yapılan analizin daha iyi anlaşılması için parametrelerin etkinliği araştırılmıştır. Bunun için ANOVA analizi sonucunda elde edilen değerler kullanılarak parametrelerin etkinlikleri belirlenmiştir. Bu amaçla her parametreye ait kareler toplamları (Adj SS) toplam kareler toplamına bölünmüş ve sonuçlar yüzdesel olarak ifade edilmiştir. Hem birinci derece model hem de ikinci dereceden tam etkileşimli model için oluşturulan etkinlik grafikleri Şekil 4'de görülmektedir.
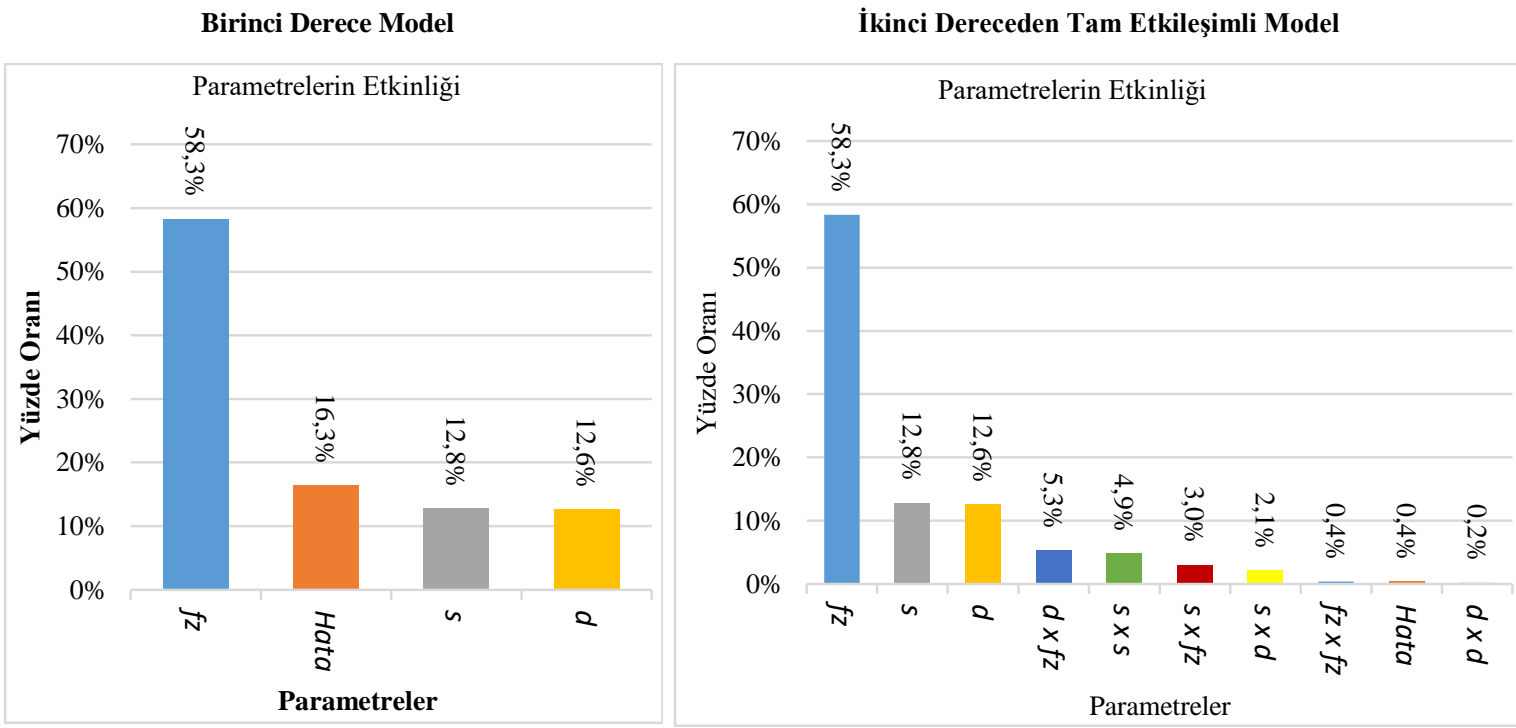

Şekil 4. Birinci ve ikinci derece modellere ait etkinlik oranları. 
Şekil 4'deki grafikler incelendiğinde, tepki kuvvetinin oluşumunda ana etkinin ilerleme miktarı parametresi olduğu açık bir şekilde görülmektedir. Her iki modelde de ilerleme miktarı parametresi \%58,3 etkinlik ile sonucu etkileyen birincil faktördür. Birinci derece modelde geriye kalan faktörlerden fener mili devri ve uç açısı değerleri sırasıla \%12,8 ve \%12,6 ile hemen hemen aynı etkinliğe sahiptir. Bununla birlikte birinci derece model bu problemin çözümünde yetersiz kalmaktadır. Çünkü \%16,3 olarak şekillenen hata oranı bu modelin kullanımını sınırlamaktadır. Birinci derece modele benzer şekilde ikinci derece modelde de fener mili devri ve uç açısı sırasıyla $\% 12,8$ ve \%12,6 değerleri ile aynı etkinliğe sahiptir. Bu iki model arasındaki fark hata oranının ikinci derece modelde oldukça düşük $(\% 0,4)$ olmasıdır. İkinci derece modelin diğer parametresi olan uç açısı ile ilerleme miktarının etkileşimi \%5,3 etkinliğe sahiptir. Fener mili devrinin kendisi ile olan etkileşimi, ilerleme miktarı ve uç açısı ile sırasıyla \%4,9, \%3 ve \%2,1 etkinliğe sahiptir. İkinci dereceden tam etkileşimli modelin diğer parametreleri olan ilerleme miktarı ve uç açısı parametrelerini kendileri ile olan etkinliği sırası ile \%0,4 ve \%0,2 ile oldukça düşük etkinliğe sahiptir.

$\mathrm{Bu}$ çalışmada kullanılan birinci derece ve ikinci dereceden tam etkileşimli denklemler kullanılarak modellere ait hesaplama formülleri Eşitlik 3 ve 4'de görülmektedir. Modellerin birbirleri ile kıyaslanmasında kullanılabilecek diğer bir araç olan regresyon analizi her iki modele de uygulanmış ve bu analizlerin sonuçları Tablo 5'de sunulmuştur.

$$
\begin{aligned}
& F=985-0,2189 \times s-4,82 \times d-7477 \times f z \\
& \begin{array}{l}
F=599-1,940 \times s+8,11 \times d+31870 \times f z+0,0005 \times s^{2}-0,0531 \times d^{2}+36598 \times f z^{2}+0,00703 \times \\
s \times d-5,979 \times s \times f z-176,9 \times d \times f z
\end{array} \\
& \quad \quad \mathrm{~F}=\text { İtme Kuvveti; } \quad \mathrm{s}=\text { Fener Mili Devri; } \quad \mathrm{d}=\text { Uç Açısı; } \quad \text { fz }=\text { İlerleme Miktarı; }
\end{aligned}
$$

Tablo 5. Modellere ait $\mathrm{R}^{2}$ değerleri.

\begin{tabular}{|l|l|l|l|}
\hline Model & $\mathrm{R}^{2}$ & $\mathrm{R}^{2}(\operatorname{adj})$ & $\mathrm{R}^{2}($ tahmin) \\
\hline Birinci Derecede Model & $83,67 \%$ & $79,22 \%$ & $66,31 \%$ \\
\hline Tam etkileşimli Model & $99,61 \%$ & $98,92 \%$ & $93,82 \%$ \\
\hline
\end{tabular}

Tablo 5'den de anlaşılabileceği gibi 1. dereceden modele ait R2 değerleri kabul edilebilir değerlerin altındadır. Birinci derecede modele ait ANOVA analizde oluşan yüksek hata oranı ve düşük R2 değeri ile bu modelin bu deney sistemi için kullanılmayacağ1 görülmektedir. İkinci derece model ise yüksek R2 değerleri ile etkin olarak kullanılabilir. Bu nedenle deneylerde kullanılan parametrelerinin etkinliği ile ilgili inceleme yapılması ve deney sonuçlarının tahmin yeterliliğinin ölçülmesinde için ikinci derece model kullanılmıştır. Tam etkileşimli model ile parametrelerdeki değişimin analiz edilmesi için Şekil 5'de görülen grafikler kullanılmıştır.

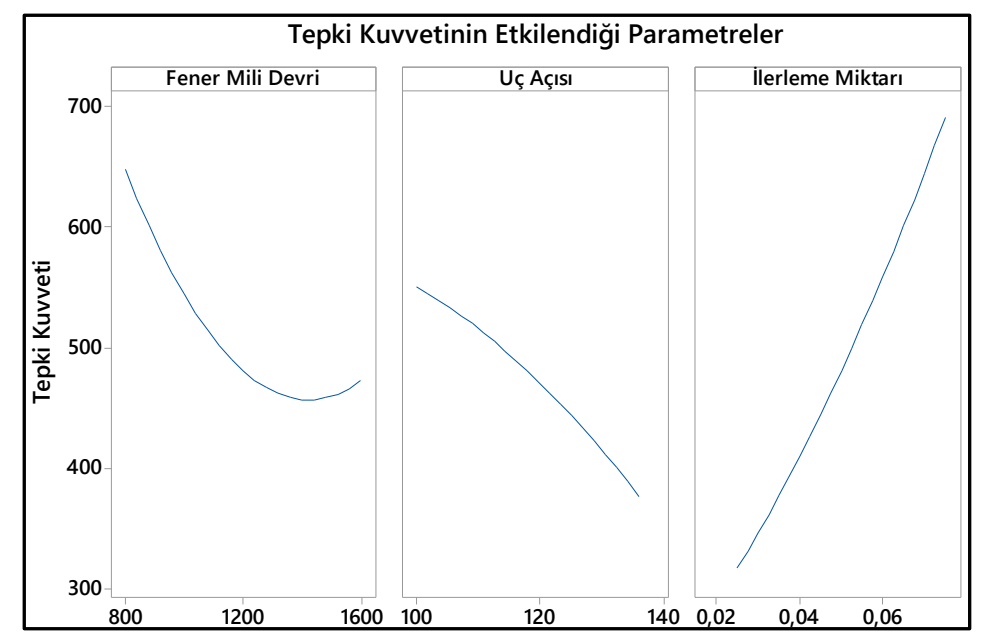

Şekil 5. Parametre değişiminin etkisi. 
Şekil 5'de görüldüğü gibi her üç parametrenin de değişimi tepki kuvvetlerinin değişimine neden olmaktadır. Bununla birlikte fener mili devri ve uç açısı parametrenin değişimi Şekil 4'de verilen etkinlik oranları grafiğine benzer şekilde tepki kuvveti üzerinde sınırlı bir etki oluşturmaktadır. İlerleme miktarı parametresindeki değişim ise neredeyse lineer çizgi görünümlü bir eğri oluşturmakta ve artan ilerleme miktarı doğrudan tepki kuvvetini artırmaktadır. Bu durum literatürde gerçekleştirilen çalışmalar ile paralellik göstermektedir [9-10, 13]. Fener mili devri parametresinin artmasına bağlı olarak tepki kuvveti düşmektedir. Bununla birlikte fener mili devrinin en yüksek değerinde belirli bir tepki kuvveti artışı gözlenmektedir. Ancak bu durum genel eğilimi bozmamaktadır. Uç açısı parametresinde ise en düşük tepki kuvveti en büyük uç açısı ile sağlanmıştır. Parametrelerin birbiri ile ilişkilerinin anlaşılması için oluşturulan grafikler ve bu grafiklerin analizi Tablo 6 'da verilmiştir.

Tablo 6. Parametrelerin birbiri ile ilişkileri.

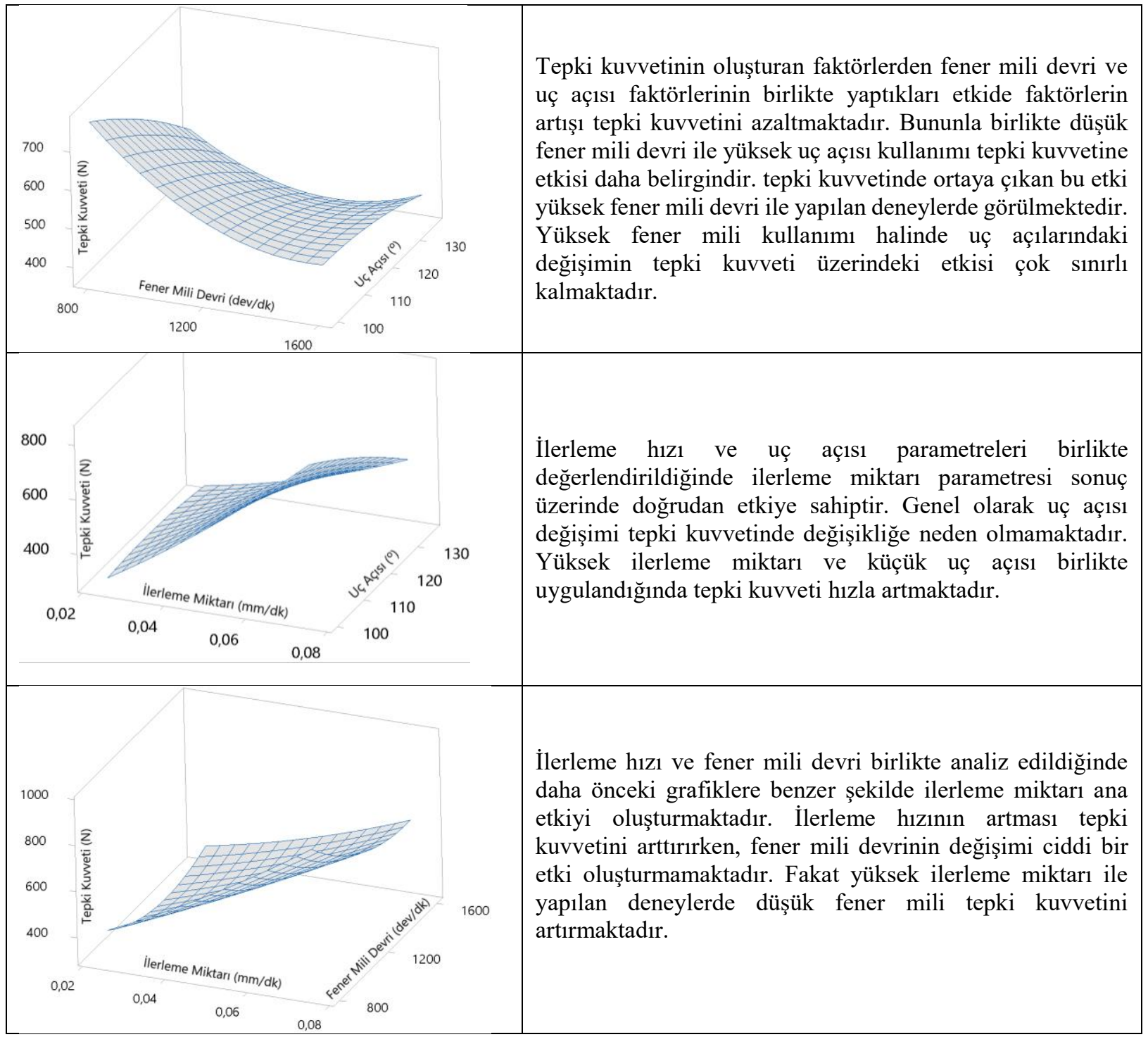

Genel olarak parametrelerin birbiri ile ilişkilerinde ilerleme miktarı ana faktör olarak göze çarpmaktadır. Ayrıca ilerleme miktarı parametresi dışındaki parametrelerin sonuca etkisi sınırlı olmaktadır. Ancak yüksek ilerleme miktarı ile yapılan deneylerde ilgi çekici şekilde diğer parametrelerin etkinliği artmaktadır. Bu durumda düşük uç açısı ve düşük fener mili sonuç üzerinde olumsuz etki oluşturmaktadır. Deneylerde hedeflenen en düşük tepki kuvvetini elde etmek için bu parametrenin hangi değerlerde kullanılması gerektiğini gösteren değerler ve grafikler Şekil 6'da verilmiştir. 


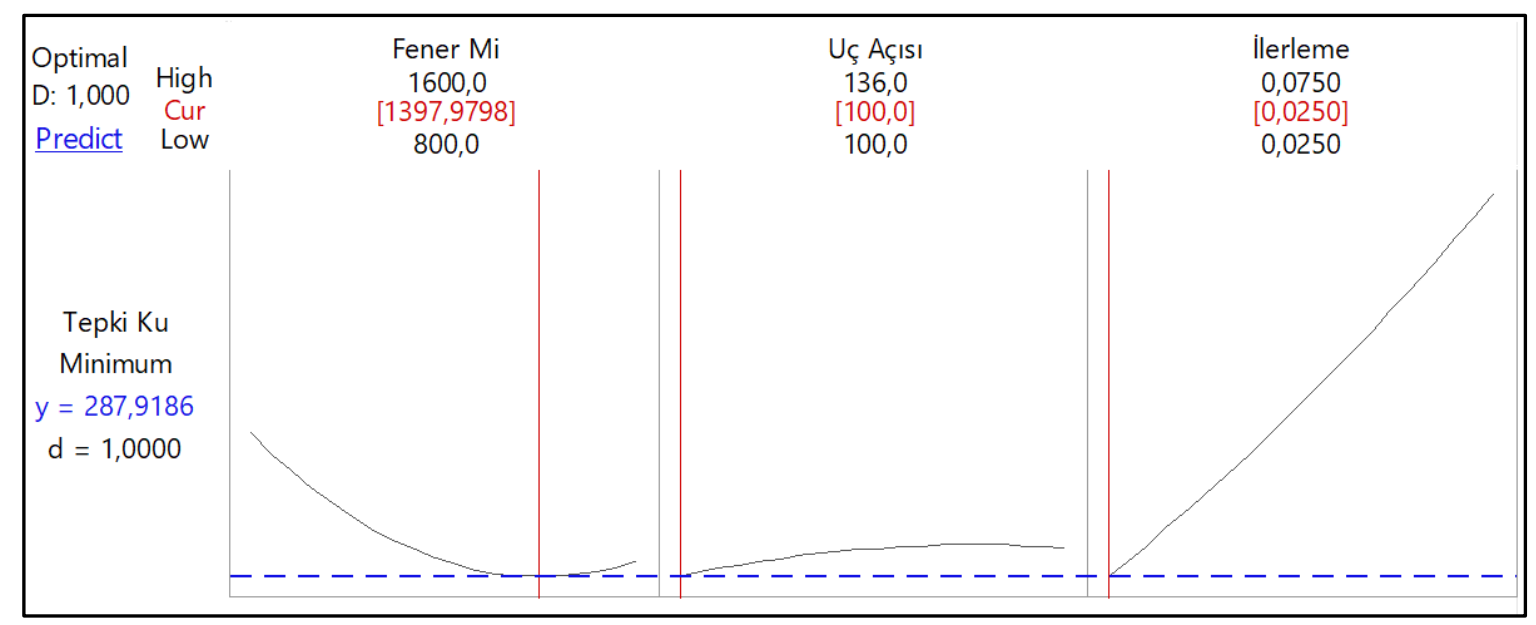

Şekil 6. Düşük tepki kuvvetini oluşturan parametre değerleri.

Şekil 6'daki grafikler incelendiğinde mevcut deney şartlarında oluşabilecek en düşük tepki kuvveti yaklaşık $288 \mathrm{~N}$ olarak görülmektedir. Bu kuvvetin elde edilmesi için fener mili devrinin yaklaşık 1400 dev/dak, uç açısının $100^{\circ}$ ve ilerleme miktarı parametresinin ise $0,025 \mathrm{~mm} /$ dak olarak seçilmesi gerekmektedir. Bununla birlikte kaçınılması gereken yüksek tepki kuvvetinin en yüksek olduğu durumda ayrıca Şekil 7'de görülmektedir.

Şekil 7'deki grafiklerde de görüldüğü gibi en yüksek tepki kuvveti yaklaşık olarak $1117 \mathrm{~N}$ dur. Yüksek tepki kuvvetleri talaşlı imalat işlemlerinde istenmeyen bir durumdur. Fener mili devrinin $800 \mathrm{dev} / \mathrm{dak}$ Uç açısının $100^{\circ}$ ve ilerleme miktarının 0,075 mm/dak olması en yüksek tepki kuvvetinin oluşuma neden olmaktadır.

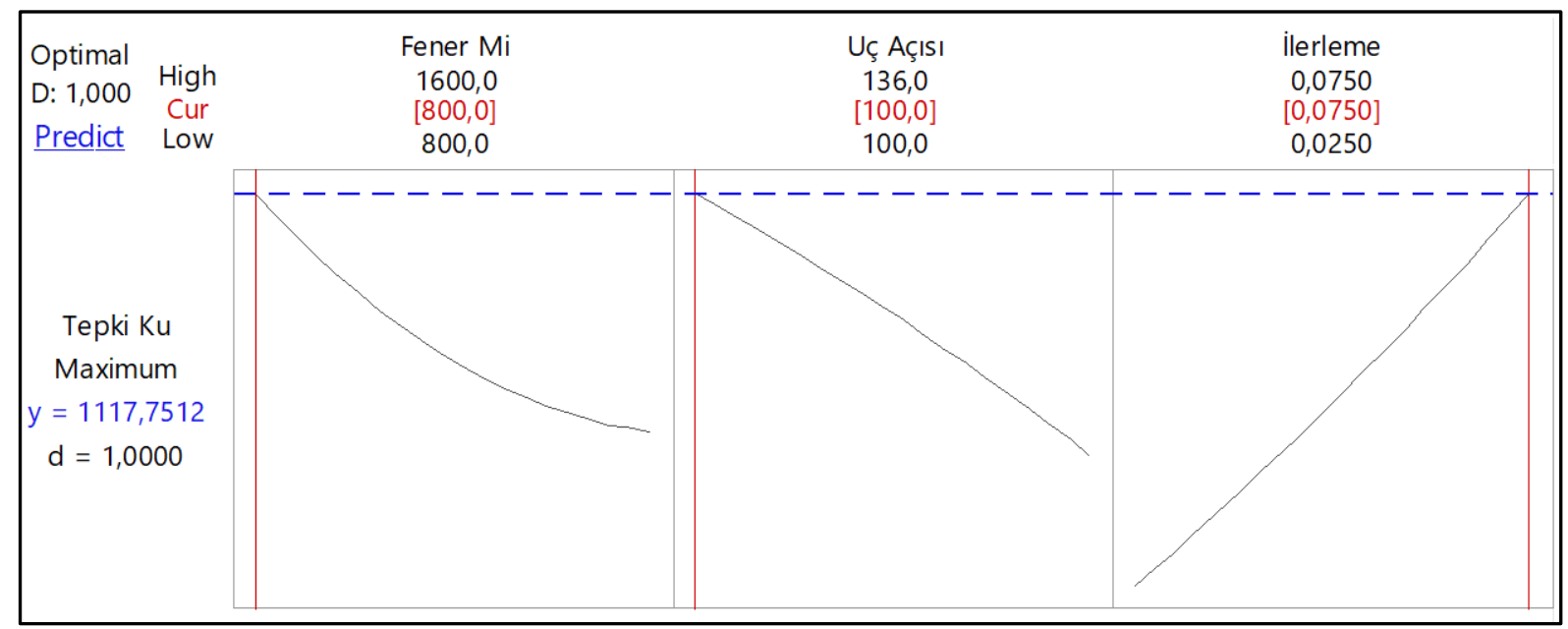

Şekil 7. Yüksek tepki kuvvetini oluşturan parametre değerleri.

Oluşturulan modelin tahmin yeteneği bu modelin uygulana bilirliğinin analizinde oldukça önemlidir. Deney verileri içinden seçilen rasgele veriler kullanılarak modelin tahmin yeteneği incelenmiştir. Model ile hesaplanan sonuçlar ve bu sonuçların deney sonuçlarına yakınsama miktarı grafiksel olarak Tablo 7'de görülmektedir.

Tablo 7 incelendiğinde tahminlerin 0,964 R2 değeri ile yüksek tutarlılıkla gösterdiği görülmektedir. Tahminlerin yüzde yakınsaması ise \%91 olarak şekillenmiştir. Grafik incelendiğinde ise deney sonuçları ile tahminler aynı grafik içerisinde benzer noktalarda oluşmaktadır. Daha yüksek R2 değerine ulaşılması için deney şartlarının iyileştirilmesi modele ait tahmin yeteneğini arttırabilecektir. 
Tablo 7. Modelin Tahmin Yeteneği.

\begin{tabular}{|c|c|c|c|c|c|c|}
\hline \multicolumn{4}{|c|}{ Rasgele Seçilen Deney Verilerine ait Tahminler } & \multirow{3}{*}{1200} & \multirow{2}{*}{$\begin{array}{l}\text { Tahmin Yeteneği ve Sonuçları } \\
\text { (Rasgele Seçilen Veriler) }\end{array}$} & \\
\hline $\begin{array}{l}\text { Deney } \\
\text { No }\end{array}$ & $\begin{array}{l}\text { Deney } \\
\text { Sonuçları }\end{array}$ & Tahminler & $\begin{array}{l}\text { Yüzde Tahmin } \\
\text { Yeteneği }\end{array}$ & & & \\
\hline 1 & 472,43 & 465,069 & $\% 98$ & & & \\
\hline 2 & 274,7 & 308,261 & $\% 88$ & \multirow{3}{*}{$\overbrace{\bar{Z}}^{1000} 800$} & & \\
\hline 3 & 420,25 & 349,429 & $\% 83$ & & & \\
\hline 4 & 414,92 & 473,133 & $\% 86$ & & & \\
\hline 5 & 435,84 & 377,306 & $\% 87$ & & & \\
\hline 6 & 985,04 & 1117,751 & $\% 87$ & & & \\
\hline 7 & 697,6 & 721,794 & $\% 97$ & 200 & & \\
\hline 8 & 490,27 & 490,134 & $\% 100$ & 0 & & \\
\hline \multicolumn{3}{|c|}{ Ortalama Yüzde Tahmin Yeteneği } & $\% 91$ & & \multirow{2}{*}{ 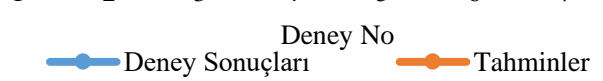 } & 8 \\
\hline \multicolumn{3}{|c|}{$\mathrm{R}^{2}$ Değeri } & 0,964 & & & \\
\hline
\end{tabular}

\section{Sonuçlar}

$\mathrm{Bu}$ çalı̧̧mada, tepki kuvveti üzerinde etkiye sahip fener mili devri, kesici uç açısı ve ilerleme miktarı parametrelerinin değişiminin analizi elde edilmiştir. Oluşturulan modellerden gerek lineer modelde gerekse ikinci derece modelde en etkin parametre ilerleme miktarı parametresidir. Bununla birlikte lineer modelin yüksek hata oranı ve düşük R2 değerleri ile bu problemin çözümlenmesi amacıyla kullanılması uygun olmayacağı sonucuna varılmıştır. Parametrelerin etkinliği değerlendirildiğinde en etkin parametre olan ilerleme miktarı parametresinin artması tepki kuvvetini önemli oranda (ortalama \%225) arttırmaktadır. Fener mili devri ve kesici uç açısındaki artışlar ise tepki kuvvetini düşürmekte fakat bu etki ilerleme miktarı parametresinin etkisi kadar belirgin olmamaktadır. Parametrelerin birlikte incelendiğinde ilerleme miktarı dışındaki parametrelerin sonuç üzerinde sınırlı etkiye sahip olduğu yüksek ilerleme miktarı düşük kesici uç açısının ve düşük fener mili devrinin tepki kuvvetini arttıracağı gözlemlenmiştir. Talaşlı imalat için istenen düşük tepki kuvvetinin oluşmasında düşük uç açısı ve düşük ilerleme miktarı değerlerinin yanında yüksek fener mili devrinin tercih edilmesi gerektiği anlaşılmaktadır. Deney sonuçları ile tahmin sonuçları karşılaştırıldığında modelin oluşturulmasında uygulanan yüzey yanıt yönteminin bu problemin modellenmesinde başarılı bir şekilde kullanılabileceği gözlemlenmiştir.

\section{Kaynaklar}

[1] Chen WC, Tsao CC. Cutting performance of different coated twist drills. J Mater. Process Technol 1999; 88: 203 - 207.

[2] Lazar MB, Xiraouchhakis P. Mechanical load distribution along the main cutting-edges in drilling. J Mater Process Technol 2013; 213: $245-260$.

[3] Kalidas S, Devor RE, Kapoor SG. Experimental investigation of the effect of drilling coatings on hole quality under dry and wet drilling conditions. Surf Coat Technol 2001; 148:117 - 128.

[4] Palanikumar K, Muniaraj A. Experimental investigation and analysis of thrust force in drilling cast hybrid metal matrix (Al-15\%SiC-4\%fraphite) composites. Measurement 2014; 53: $240-250$.

[5] Sui J, Kountanya R, Guo C. Development of a mechanistic force model for CNC drilling process Simulation. Procedia Manuf 2016; 5: 787 - 797

[6] Çelik YH, Yildiz H. Effect of cutting parameters on workpiece and tool properties during drilling of Ti-6Al-4V. Wear Test 2016; 58: $519-525$.

[7] Ema S. Effect of twist drill point geometry on torque and thrust. Sci Rep Edu Gifu Univ 2012; 36: 165 - 174.

[8] Ghosh R, Sarkar R, Paul SS, Pal K. Biocompatibility and drilling performance of beta tricalcium phosphate: Yttrium phosphate bioceramic composite. Ceram Int 2016; 42: 8263 - 8273.

[9] Çaydaş U Çelik M. Investigation of the effects of cutting parameters on the surface roughness, tool temperature and thrust force in drilling of AA-T6 alloy. J Polytech 2017; 20 (2): 419 - 425.

[10] Kyratsis P, Markopoulos AP, Efkolidis N, Maliagkas V, Kakoulis K. Prediction of Thrust Force and Cutting Torque in Drilling Based on the Response Surface Methodology. Machines 2018; 6(24): 1-12. 
[11] Raja R, Krishnadraj V, Jannet S. Experimental Investigation of High Speed Drilling on GFRP/Aluminium Multi Material., Indian J Sci Technol 2017; 10(47): 1-9.

[12] Efkolidis N, Hernández CG, Talón JLH, Kyratsis P. Modelling and Prediction of Thrust Force and Torque in Drilling Operations of Al7075 Using ANN and RSM Methodologies., Strojniški vestnik - J Mech Engin 2018; 64(6): 351-361.

[13] Valarmathi TN, Palanikumar K, Sekar S. Modelling of thrust force in drilling of plain medium density fiberboard (MDF) composite panels using RSM. Procedia Engin 2012; 38: 1828 - 1835.

[14] Palanikumar K, Muniaraj A. Experimental investigation and analysis of thrust force in drilling cast hybrid metal matrix (Al-15\% SiC-4\%graphite) composites. Measurement 2014; 53: 240-250.

[15] Chaudhary G, Kumar M, Verma S, Srivastav A. Optimization of drilling parameters of hybrid metal matrix composites using response surface methodology. Procedia Mater Sci 2014; 6: 229 - 237.

[16] Anarghya A, Harshith DN, Nitish RS, Nayak N, Gurumurthy BM, Abhishek VNS, Patil IG. Thrust and torque force analysis in the drilling of aramid fibre-reinforced composite laminates using RSM and MLPNN-GA. Heliyon 2018; 4(11), e00938.

[17] Shuang Y, Guangxian L, Songlin D, John M. Performance and mechanisms of graphene oxide suspended cutting fluid in the drilling of titanium alloy Ti-6Al-4V. J Manuf Process 2017; 29: 182-193. 